\title{
ANALISIS RELAKSASI PERNAFASAN TERHADAP KECEMASAN PADA IBU HAMIL TRIMESTER III
}

\author{
Ayunin Syahida ${ }^{1^{*}}$, Nanda Mirani² \\ 1,2Prodi DIII Kebidanan STIKes Bustanul Ulum Langsa \\ *Koresponden Email: ayunin.syahida@gmail.com
}

\section{ABSTRACT ANALYSIS BREATHING RELAXATION ON ANXIETY IN PREGNANT WOMEN IN TRIMESTER III}

Background: During pregnancy, mothers experience physical and psychological changes that occur due to hormonal changes. The process of adjusting to new conditions experienced by pregnant women can then cause anxiety. To overcome anxiety during pregnancy, non-pharmacological options. Interventions that are often used and proven effective to reduce anxiety are breathing relaxation techniques. Pregnant women who experience anxiety, the possibility of the baby being born can be premature, underweight, or swollen due to excess sodium (pre-eclampsia). Some pregnant women in the third trimester who made a pregnancy visit expressed anxiety about the conditions experienced during this pregnancy and also worried about facing childbirth in the future.

Purpose: This study aims to determine the analysis Breathing Relaxation on Anxiety in Pregnant Women in Trimester III.

Methods: The designs used in this study were quasi-experimental designs (quasi-experimental) with a one group pre-test and post-test design approach. The number of research samples was 15 third trimester pregnant women. The sampling technique used was purposive sampling technique. The research instrument used in this study was a questionnaire consisting of the demographic identity of the respondents, respiratory relaxation SOPs and about anxiety using the PASS (Perinatal Anxiety Screening Scale) scale. Data analysis was carried out univariate and bivariate using the Paired T-Test.

Results: The results showed that the level of anxiety was known to have a $p$ value $(\mathrm{sig})(0.000)<0.05$, which means that there is an effect of breathing relaxation on anxiety in trimester III pregnant women.

Conclusion: There is an effect of breathing relaxation on anxiety in trimester III pregnant women. It is hoped that health workers will increase counseling about pregnancy, especially about problems that can occur during pregnancy so that mothers can be more relaxed in dealing with pregnancy and childbirth.

Suggestion It is expected that health workers will provide counseling to mothers who will give birth about breathing relaxation methods, to anticipate anxiety and fear in mothers and provide information about preparation for childbirth, both physically and psychologically calm or relaxed so that childbirth can run safely and smoothly.

Keywords: Breathing Relaxation, Anxiety, Pregnant

\section{ABSTRAK}

Latar Belakang: Selama kehamilan ibu mengalami perubahan fisik dan psikis yang terjadi akibat perubahan hormon. Proses penyesuaian diri terhadap keadaan baru yang dialami ibu hamil ini kemudian dapat menimbulkan kecemasan. Untuk mengatasi kecemasan pada saat hamil, pilihan non farmakologis. Intervensi yang sering di gunakan dan terbukti efektif untuk mengurangi kecemasan adalah teknik relaksasi pernafasan. Ibu hamil yang mengalami kecemasan, kemungkinan bayi yang dilahirkan bisa prematur, berat badan kurang, atau bengkak-bengkak karena kelebihan natrium (pre eklampsi). Beberapa ibu hamil pada trimester III yang melakukan kunjungan kehamilan menyatakan cemas dengan kondisi yang dialami saat kehamilan ini dan juga cemas akan menghadapi persalinan kedepannya.

Tujuan: Penelitian ini bertujuan untuk menganalisis Relaksasi Pernafasan Terhadap Kecemasan Pada Ibu Hamil Trimester III.

Metode: Desain yang digunakan dalam penelitian ini adalah quasi eksperiment designs (eksperimen semu) dengan pendekatan one group pre test and post test design. Jumlah sampel penelitian sebanyak 15 ibu hamil trimester III. Teknik sampling yang digunakan teknik purposive sampling. Instrument penelitian yang digunakan dalam penelitian ini adalah kuesioner yang terdiri dari indentitas demografi responden, SOP relaksasi pernafasan dan tentang kecemasan menggunakan skala PASS (Perinatal Anxiety Screening Scale). Analisis data dilakukan secara univariat dan bivariat menggunakan uji Paired T-Test. 


\section{JKM (Jurnal Kebidanan Malahayati),Vol 7,No.4.Oktober 2021, ISSN (Print) 2476-8944 ISSN (Online) 2579-762X, Hal 634-641}

Hasil:Hasil penelitian didapatkan bahwa tingkat kecemasan diketahui nilai $p(\operatorname{sig})(0,000)<0,05$ yang artinya terdapat pengaruh relaksasi pernafasan terhadap kecemasan pada ibu hamil trimester III.

Kesimpulan: Ada pengaruh kombinasi relaksasi pernafasan dan dzikir terhadap kecemasan pada ibu hamil trimester III. Diharapkan agar tenaga kesehatan lebih meningkatkan penyuluhan tentang kehamilan terutama tentang masalah-masalah yang dapat terjadi pada masa kehamilan sehingga ibu dapat lebih santai dalam menghadapi masa kehamilan dan persalinan.

Saran Diharapkan tenaga kesehatan melakukan konseling kepada ibu yang akan bersalin tentang metode relaksasi pernapasan, untuk mengantisipasi kecemasan serta rasa takut pada ibu serta memberikan informasi tentang persiapan persalinan baik fisik dan psikis yang tenang atau rileks agar persalinan dapat berjalan dengan aman dan lancar.

Kata Kunci: Relaksasi Pernafasan, Kecemasan, Kehamilan

\section{PENDAHULUAN}

Sustainable Development Goals (SDGs) merupakan program pemerintah yang salah satu tujuannya adalah meningkatkan kesehatan ibu, program ini diharapkan terwujud pada tahun 2030. Masalah kesehatan ibu menjadi kendala utama yang dirasakan oleh masyarakat (Said, 2017).

Berdasarkan data dari World Health Organization (WHO) pada tahun 2019, angka kematian ibu (AKI) mencapai 289.000 (Warta Kesehatan, 2018). Menurut Survei Demografi dan Kesehatan Indonesia (SDKI) tahun 2012, Angka Kematian Ibu (AKI) di Indonesia mencapai 359 per 100.000 kelahiran hidup $(0,359 \%)$ (Kemenkes RI, 2018).

Pemerintah menargetkan untuk mengurangi angka kematian ibu dari 390 per 100.000 kelahiran hidup dan menargetkan menjadi 225 per 100.000 di tahun 2025. Di Indonesia pada tahun 2015 prevalensi risiko kejadian depresi atau kecemasan dalam menghadapi persalinan pervaginam sebesar $10-25 \%$ yang banyak terjadi pada wanita umur 20-44 tahun. Kejadian depresi atau kecemasan mempersulit proses persalinan sekitar 10-15\%, sedangkan kecemasan yang terjadi pada pasien operasi seksio sesarea sekitar $15-25 \%$. Angka kematian kelahiran pervaginam 95-120 per 100.000 kelahiran hidup pada tahun 2014 di Indonesia, sedangkan angka kematian operasi seksio sesarea di Indonesia tahun 2014 adalah 112-130 tiap 100.000 kelahiran hidup, melihat besarnya resiko yang mugkin ditimbulkan pada saat persalinan baik operasi seksio sesarea maupun pervaginam, maka hal ini dapat menyebabkan kecemasan pada pasien yang akan menghadapi persalinan (Syafrie, 2017).

Angka kematian ibu di Aceh lima tahun terakhir berfluktuasi, pada tahun 2019 mengalami kenaikan menjadi 172 per 100,000 kelahiran hidup dengan jumlah kematian ibu sebanyak 157 kasus, tertinggi di kabupaten Aceh Utara sebanyak 25 kasus di ikuti Bireuen 16 kasus, terendah di Pidie Jaya sebanyak 1 kasus. Selama tahun 2015 hingga 2019 cakupan pelayanan kesehatan ibu hamil K-4 cenderung tidak mengalami peningkatan, capaian tahun 2019 sebesar 79\%. Terdapat 8 kabupaten/kota yang persentase cakupan pelayanan kesehatan ibu hamil K-4 di atas target Rencana Strategis (Renstra) Pemerintah Aceh tahun 2019 yang sebesar $82 \%$. Capaian tertinggi berada di Kabupaten Aceh Tenggara 95\%,adapun terendah di Simeulue sebesar 59\% (Dinas Kesehatan Aceh, 2020).

Data yang diperoleh dari Dinas Kesehatan Kota Langsa jumlah ibu hamil di Kota Langsa Tahun 2020 sebanyak 3.630 ibu. Pada Puskesmas Langsa Baro sebanyak 1.109 ibu, Puskesmas Langsa Timur sebanyak 326 ibu, Puskesmas Langsa Kota sebanyak 693 ibu, Puskesmas Langsa Lama sebanyak 691 ibu dan Puskesmas Langsa Barat sebanyak 811 ibu. Menurut data Puskesmas Langsa Baro bulan Desember Tahun 2020 ibu hamil sebanyak $1109 \mathrm{ibu}$, dan ibu hamil trimester III sebanyak 1018 (91,8\%) (Dinkes Kota Langsa, 2020).

Ibu hamil yang mengalami kecemasan, kemungkinan bayi yang dilahirkan bisa prematur, berat badan kurang, atau bengkak-bengkak karena kelebihan natrium (pre eklampsi). Ibu yang cemas ketika hamil dapat meningkatkan hormon adrenalin. Gangguan akibat kecemasan yang dialami ibu akan menjadi kegawatdaruratan baik bagi ibu sendiri maupun janin dalam proses persalinannya, yang dapat menyebabkan lepasnya hormon stres. Lepasnya hormon-hormon stres tersebut mengakibatkan terjadinya vasokonstraksi sistemik, termasuk diantaranya konstraksi vasa utero plasenta yang menyebabkan gangguan aliran darah di dalam rahim, sehingga penyampaian oksigen ke dalam miometrium terganggu dan mengakibatkan lemahnya kontraksi otot rahim. Kejadian tersebut menyebabkan makin lamanya proses persalinan 
(partus lama) sehingga janin dapat mengalami kegawatan (fetaldistress). Disamping itu dengan meningkatnya plasma kortisol, berakibat menurunkan respon imun ibu dan janin. Kondisi tersebut bisa mengarah pada kematian ibu dan janin. Jika kondisi ini dibiarkan maka angka mortalitas dan morbiditas pada ibu hamil akan semakin meningkat (Niko, 2018).

Berdasarkan penelitian Kecemasan pada ibu hamil sebenarnya justru merugikan kesehatan ibu hamil dan janin yang dikandungnya. Berbagai kerugian tersebut akhirnya menyebabkan ibu hamil melahirkan bayi yang prematur dan bahkan keguguran. Sebab janin merasa gelisah dan otot rahim melemah sehingga dapat menyebabkan bayi yang dilahirkan memiliki berat badan redah (BBLR) yaitu bayi lahir dengan berat kurang dari 2500 gram. Berdasarkan Penelitian Pratiwi (2019) untuk mengetahui tingkat kecemasan ibu hamil dengan risiko melahirkan bayi berat lahir rendah di puskesmas rappang kabupaten sidenreng rappang tahun 2019 dengan hasil penelitian bahwa tingkat kecemasan responden dengan tingkat kecemasan ringan sebanyak $22(73 \%)$, kecemasan sedang sebanyak $4(13 \%)$, kecemasan verat sebanyak 1 $(3 \%)$ serta yang tidak merasakan kecemasan sebanyak $3(1 \%)$ dan analisis chi-square nilai $p$ $0,05<0,766$ sehingga tidak ada hubungan tingkat kecemasan dengan resiko melahirkan BBLR.

Intervensi yang sering di gunakan dan terbukti efektif untuk mengurangi kecemasan adalah teknik relaksasi. Pada waktu orang mengalami ketegangan dan kecemasan yang bekerja adalah sistem syaraf simpatetis, sedangkan pada waktu rileks yang bekerja adalah sistem syaraf parasimpatetis. Relaksasi berusaha mengaktifkan kerja syaraf parasimpatetis. Keadaan rileks menurunkan aktivitas amygdala, mengendurkan otot, dan melatih individu mengaktifkan kerja sistem syaraf parasimpatetis sebagai counter aktivitas sistem syaraf simpatetis (Hikmawati, 2018).

Relaksasi akan membuat individu lebih mampu menghindari reaksi yang berlebihan karena kecemasan. Mengelola dirinya dengan menjaga ketenangan emosi. Ketenangan emosi diperlukan agar seseorang memiliki waktu untuk melihat suatu situasi yang sedang dialami dengan menggunakan sudut pandang yang lebih positif. Ketenangan emosi bisa terwujud dalam keadaan aspek fisiologisnya juga berada dalam keadaan rileks (Mawardika, Rahmawati, \& Kurniawati, 2020).

Berdasarkan beberapa hasil penelitian dapat dinyatakan bahwa berbagai terapi relaksasi cukup efektif untuk menurunkan kecemasan, artinya secara non farmakologis mampu menggantikan terapi farmakologis, yang dikhawatirkan dapat memberikan efek samping tertentu yang tidak baik bagi kesehatan ibu hamil. Relaksasi pernafasan merupakan latihan pernapasan dengan teknik bernapas secara perlahan dan dalam, menggunakan otot diafragma, sehingga memungkinkan abdomen terangkat perlahan dan dada mengembang penuh. Relaksasi pernafasan ini telah terbukti mampu menjadi salah satu metode pengobatan (Mawardika et al., 2020). Dengan ini peneliti tertarik untuk melakukan penelitian yang berbeda dengan penelitian sebelumnya tanpa menggunakan metode kombinasi relaksasi dan dilakukan khusus pada ibu hamil trimester III

Penelitian ini bertujuan untuk menganalisis relaksasi pernafasan terhadap kecemasan pada ibu hamil trimester III.

\section{METODOLOGI PENELITIAN Jenis penelitian}

Jenis penelitian yang digunakan adalah quasi eksperiment designs dengan pendekatan one group pre test and post test design. Pada kelompok perlakuan akan di observasi awal (pre test) setelah itu akan di observasi akhir (post test) yang memungkinkan dapat menguji perubahan yang terjadi setelah adanya perlakuan.

\section{Tempat dan Waktu Penelitian}

Penelitian dilakukan di wilayah kerja Puskesmas Langsa Baro Kota Langsa pada bulan juni 2021.

\section{Sampel}

Sampel yang dilibatkan dalam penelitian sebanyak 15 ibu hamil trimester III,, yang diambil dengan menggunaka rumus jenis obsevasional. Pemilihan sampel menggunakan teknik purposive sampling yaitu yaitu suatu teknik pengambilan sampel berdasarkan pertimbangan kriteria inklusi dan eksklusi pada populasi penelitian. Sehingga dalam teknik sampling di sini peneliti mengambil responden pada saat itu juga.

\section{Pelaksanaan Penelitian}

Prosedur pengumpulan data yang dilakukan adalah mengajukan surat permohonan izin penelitian ke Puskesmas Langsa Baro. Setelah mendapat izin, peneliti melaksanakan pengumpulan data dengan meminta meminta persetujuan responden untuk menjadi responden dengan menandatangani informed consent. Setelah responden bersedia, peneliti kemudian mengisi lembar kuisioner data demografi yaitu nama 
(inisial), umur, psekerjaan, dan pendidikan responden melalui wawancara. Lalu, peneliti menjelaskan prosedur relaksasi pernafasan yang dilakukan oleh peneliti di dalam ruangan, dimana teknik relaksasi pernafasan dilakukan selama durasi 1 -2 menit. Untuk melihat kecemaan responden. Peneliti melakukan pengkajian kecemasan kepada responden sebelum dilakukan intervensi dan selanjutnya peneliti mengkaji hasil setelah dilakukan intervensi tentang kecemasan responden setelah diberikan teknik pernafasan. Setelah data terkumpul lalu dilakukan pengolahan data dengan bantuan program SPSS dengan uji statistik uji t-dependen Paired sample t-test untuk mengukur skala nyeri sebelum dan sesudah dilakukan relaksasi pernafasan.

\section{Instrument penelitian}

Instrument penelitian yang digunakan dalam penelitian ini adalah kuesioner yang terdiri dari indentitas demografi responden, SOP relaksasi pernafasan dan tentang kecemasan menggunakan skala PASS (Perinatal Anxiety Screening Scale) yang merupakan kuesioner baku. SOP relaksasi pernapasan ini diadopsi dari penelitian Astuti (2018).

\section{Uji Validitas dan Reliabilitas}

Alat ukur harus diuji validitas dan realibilitasnya. Dalam penelitian ini alat ukur yang digunakan adalah alat ukur yang sudah baku berdasarkan literatur sehingga tidak perlu lagi di ujivaliditas dan realibilitasnya. Alat akur skala nyeri yang digunakan adalah PASS (Perinatal Anxiety Screening Scale).

\section{Analisa data}

Analisa data dilakukan secara univariat (deskriptif) untuk melihat variabel-variabel penelitian baik independen maupun dependen dalam bentuk distribusi frekuensi dan bivariat menggunakan uji Paired T-Test untuk melihat hubungan variabel independent dengan dependent.

\section{HASIL DAN PEMBAHASAN \\ Analisis Deskriptif}

Berdasarkan tabel 1 menunjukkan gambaran kecemasan responden sebelum diberikan intervensi relaksasi pernafasan menunjukkan 5 (33,3\%) responden mempunyai tingkat kecemasan yang berat dan setelah diberikan intervensi relaksasi pernafasan menunjukkan tidak adanya responden yang mempunyai tingkat berat. Kecemasan responden sebelum diberikan intervensi relaksasi pernafasan menunjukkan $8 \quad(53,3 \%)$ responden mempunyai tingkat kecemasan yang ringan-sedang dan setelah diberikan intervensi relaksasi pernafasan menunjukkan $5(33,3 \%)$ responden mempunyai tingkat kecemasan yang ringansedang. Terjadi penurunan kecemasan pada ibu hamil setelah diberikannya intervensi relaksasi pernafasan

Tabel 1.

Distribusi Frekuensi Pretest dan Postest Kecemasan Pada Ibu Hamil Trimester III Di Wilayah Kerja Puskesmas Langsa Baro

\begin{tabular}{lcccc}
\hline \multirow{2}{*}{\multicolumn{1}{c}{ Kecemasan }} & \multicolumn{4}{c}{ Jawaban } \\
\cline { 2 - 5 } & \multicolumn{3}{c}{ Pretest } & \multicolumn{2}{c}{ Postest } \\
\cline { 2 - 5 } & $\mathbf{N}$ & $\%$ & $\mathbf{N}$ & $\%$ \\
\hline Kecemasan Berat (skor 42-93) & 5 & 33,3 & 0 & 0 \\
Kecemasan Ringan-Sedang (skor 21-41) & 8 & 53,3 & 5 & 33,3 \\
Tidak ada gejala (skor 0-20) & 2 & 13,3 & 10 & 66,7 \\
\hline
\end{tabular}

\section{Analisis Bivariat}

Berdasarkan Tabel 2 dapat dilihat bahwa data nilai pretest kecemasan ibu hamil berdistribusi normal dengan nilai $P=0,275$ ( $P>0,05)$, demikian juga dengan data nilai postest kecemasan ibu hamil dengan nilai $P=0,329(P>0,05)$. Karena semua data yang akan dianalisis berdistribusi normal maka uji bivariat yang digunakan adalah dengan menggunakan Uji paired sample T- Test.

Tabel 2.

Uji Normalitas Data 


\begin{tabular}{ccccc}
\hline \multirow{2}{*}{ Uji Normalitas } & \multicolumn{3}{c}{ Shapiro-Wilk } & \multirow{2}{*}{ Keterangan } \\
\cline { 2 - 4 } & Statistik & df & Sig & \\
\hline Pretest & 0,930 & 15 & 0,275 & Normal \\
Postest & 0,935 & 15 & 0,329 & Normal \\
\hline
\end{tabular}

Berdasarkan tabel 3 dapat dilihat bahwa pada tingkat kecemasan diketahui nilai $p$ (sig) $(0,000)<0,05$ yang artinya terdapat pengaruh relaksasi pernafasan terhadap kecemasan pada ibu hamil trimester III. Rata-rata skor kecemasan sebelum diberikan intervensi dengan relaksasi pernafasan sebesar 44,60 dan setelah diberikan intervensi dengan relaksasi pernafasan skor ratarata kecemasan menurun menjadi 20,46, hal ini menunjukkan relaksasi pernafasan efektif dalam mengurangi kecemasan pada ibu hamil trimester III.

Tabel 3.

Distribusi Rata-Rata Skor Kecemasan Pada Ibu Hamil Trimester III Sebelum dan Sesudah Diberikan Relaksasi Pernafasan di Wilayah Kerja Puskesmas Langsa Baro

\begin{tabular}{ccc}
\hline & Kecemasan & P \\
\cline { 1 - 2 } Sebelum & Sesudah & \\
\hline Mean SD & Mean SD
\end{tabular}

\begin{tabular}{lllll}
\hline 44,60 & 18,26 & 20,46 & 9,03 & 0,000 \\
\hline
\end{tabular}

\section{PEMBAHASAN}

Tingkat Kecemasan Pada Ibu Hamil Trimester III Sebelum Terapi Relaksasi Pernafasan

Pada penelitiannya terfokus pada ibu hamil trimester III dan teknik relaksasi yang digunakan hanya teknik relaksasi pernafasan tanpa menggunakan kombinasi relaksasi lain agar ibu hamil juga dapat menerapkan dengan mudah dalam kesehariannya.

Penelitian ini menggunakan tahapan penelitian dengan mengajarkan ibu hamil trimester III untuk melakukan pernapasan secara diagfragma agar mengalami perasaan stabil dan tenang. Pertama peneliti membawa ibu ketempat yang tenang atau sepi (bebas dari suara bising atau bau yang menyengat), selanjutnya iresponden diajarkan cara mengambil posisi yang nyaman yaitu duduk bersila dengan tangan diletakkan di lutut kaki dengan tubuh dalam keadaan rileks dan mata terpejam, kemudian pikiran dalam keadaan kosong dan selanjutnya melakukan pemusatan pikiran/konsentrasi dan selanjutnya diajarkan cara gerakan napas secara diagfragma secara terus menerus sehingga ibu mengalami perasaan tenang serta rileks.

Berdasarkan hasil penelitian ditemukan gambaran kecemasan responden sebelum diberikan intervensi kombinasi relaksasi pernafasan menunjukkan $5(33,3 \%)$ responden mempunyai tingkat kecemasan yang berat dan setelah diberikan intervensi kombinasi relaksasi pernafasan menunjukkan tidak adanya responden yang mempunyai tingkat berat. Kecemasan responden sebelum diberikan intervensi relaksasi pernafasan menunjukkan $8 \quad(53,3 \%)$ responden mempunyai tingkat kecemasan yang ringan-sedang dan setelah diberikan intervensi relaksasi pernafasan menunjukkan $5(33,3 \%)$ responden mempunyai tingkat kecemasan yang ringan-sedang. Terjadi penurunan kecemasan pada ibu hamil setelah diberikannya intervensi relaksasi pernafasan.

Hasil penelitian ini menunjukkan bahwa banyak ibu hamil yang mengalami kecemasan sebelum diberikan relaksasi pernafasan. Hal ini sesuai dengan pendapat Na'im (2010) yang menyatakan sebagian besar ibu hamil primigravida berada dalam keadaan cemas yang nyata. Mereka belum pernah merasakan perasaan kecemasan seperti ini sebelumnya dan ada sebagian yang mampu beradaptasi atau mengatasi kecemasan dengan baik. Alasan yang mungkin menyebabkan peningkatan kecemasan adalah kecemasan mengenai ketakutan untuk melahirkan dan kekhawatiran terhadap anaknya.

Menurut Hani (2010) trimester ketiga biasanya disebut periode menunggu dan waspada sebab pada saat itu ibu tidak sabar menunggu kehadiran bayinya. Gerakan bayi dan membesarnya perut merupakan dua hal yang mengingatkan ibu akan bayinya. Kadang-kadang ibu merasakan khawatir bahwa bayinya akan lahir sewaktu-waktu. Ini menyebabkan ibu meningkatkan kewaspadaan akan timbulnya tanda dan gejala terjadinya persalinan pada ibu. Seringkali ibu merasa khawatir atau takut kalau bayi yang akan dilahirkannya tidak normal. Kebanyakan ibu juga akan bersikap melindungi bayinya dan akan menghindari orang atau benda apa saja yang dianggap membahayakan bayinya. Seorang ibu mungkin mulai merasa takut akan rasa sakit dan bahaya fisik yang akan timbul pada nwaktu melahirkan. 


\section{JKM (Jurnal Kebidanan Malahayati),Vol 7,No.4.Oktober 2021, \\ ISSN (Print) 2476-8944 ISSN (Online) 2579-762X, Hal 634-641}

Berdasarkan hasil penelitian yang peneliti temukan tentang kecemasan ibu hamil primigravida trimester III sebelum diberikan terapi relaksasi pernafasan, banyak ibu yang merasa gelisah, takut, sulit tidur, selalu memikirkan tentang proses persalinan yang akan menyakitkan serta ketakutan akan mengalami persalinan yang sulit.

\section{Tingkat Kecemasan Pada Ibu Hamil Trimester III Sesudah Terapi Relaksasi Pernafasan}

Berdasarkan hasil penelitian ditemukan gambaran kecemasan responden sesudah diberikan intervensi relaksasi pernafasan menunjukkan $10(66,7 \%)$ responden tidak ada gejala kecemasan, $5(33,3 \%)$ responden dengan kecemasan ringan-sedang dan tidak ada responden dengan kecemasan berat.

Hasil ini sejalan dengan penelitian Syufian (2019) tentang "Pengaruh Terapi Zikir terhadap tingkat Kecemasan Pasien Pre Operasi Sectio Caesarea Di RSUD Dr. H. Moch. Ansari Saleh Banjarmasin". Dari hasil penelitian didapatkan sebanyak 16 responden $(45,8 \%)$ berada pada tingkat kecemasan ringan, sebanyak 11 responden $(31,4 \%)$ berada pada tingkat tidak cemas, dan sebanyak 8 responden $(22,9 \%)$ berada pada tingkat kecemasan sedang.

Penelitian ini menunjukkan bahwa sesudah diberikan terapi relaksasi pernafasan banyak ibu hamil yang sudah merasa tidak cemas, dan tidak ada ibu hamil yang masih mengalami kecemasan yang berat. Hal ini sejalan dengan pendapat Anggraieni (2014) yang menyatakan bahwa zikir memiliki daya relaksasi yang dapat mengurangi ketegangan (kecemasan) dan mendatangkan ketenangan jiwa.

Hasil Fenomena dilapangan yang peneliti temukan banyak ibu yang sudah tidak merasa gelisah, sudah tidak mengalami ketakutan, sudah tidak bermimpi mimpi yang menakutkan tentang persalinan, ibu sudah lebih tenang dan siap akan menghadapi peralinan dan berfikir positif tentang keadaan atau kondisi bayi yang akan dilahirkan serta persalinan yang lancar. Dengan hal ini membuktikan bahwa relaksasi membuat individu lebih mampu menghindari kecemasan yang berlebihan serta mampu mengelola dirinya dengan menjaga ketenangan emosi dan pikirannya.

\section{Pengaruh Relaksasi Pernafasan Terhadap Kecemasan Pada Ibu Hamil Trimester III \\ Hasil penelitian menunjukkan bahwa pada tingkat kecemasan diketahui nilai $p(\mathrm{sig})(0,000)<$ 0,05 yang artinya terdapat pengaruh relaksasi pernafasan terhadap kecemasan pada ibu hamil}

trimester III. Rata-rata skor kecemasan sebelum diberikan intervensi dengan relaksasi pernafasan sebesar 44,60 dan setelah diberikan intervensi dengan relaksasi pernafasan skor rata-rata kecemasan menurun menjadi 20,46, hal ini menunjukkan kombinasi relaksasi pernafasan efektif dalam mengurangi kecemasan pada ibu hamil trimester III.

Menurut penelitian Kuswaningsih (2020) dengan judul pengaruh teknik relaksasi nafas dalam terhadap kecemasan pada ibu hamil dengan hipertensi di Puskesmas Prangat Kabupaten Kutai Kartanegara dengan hasil penelitian menunjukkan skor rata-rata tingkat kecemasan pada ibu hamil dengan hipertensi sebelum melakukan teknik relaksasi nafas dalam yaitu 15,89 dengan kriteria tingkat kecemasan ringan dan sedang yang masing-masing berjumlah 9 orang (50\%). Kemudian sesudah melakukan teknik relaksasi nafas dalam mengalami penurunan menjadi 11,22 dengan kriteria sebagian besar tingkat kecemasan ringan berjumlah 9 orang $(50 \%)$, kemudian tidak ada gejala berjumlah 5 orang $(27,8 \%)$ dan tingkat kecemasan sedang berjumlah 4 orang $(22,2 \%)$. Kesimpulan penelitian terdapat pengaruh teknik relaksasi nafas dalam terhadap kecemasan pada ibu hamil dengan hipertensi.

Relaksasi merupakan metode efektif mengurangi kecemasan. Keteraturan dalam bernafas menyebabkan sikap mental dan badan menjadi rileks, sehingga dapat membantu mengurangi kecemasan pada ibu hamil. Teknik Relaksasi nafas dapat meningkatkan ventilasi alveoli, memelihara pertukaran gas, mencegah atelektasi paru, meningkatkan efsisiensi batuk, mengurangi stress baik stress fisik maupun emosional. Berdasarkan hal tersebut, dapat dinyatakan bahwa teknik relaksasi nafas efektif digunakan untuk mengurangi kecemasan termasuk kecemasan pada lbu hamil. Selain itu, teknik ini dapat dijadikan alternatif pilihan pertama untuk mengurangi kecemasan pada ibu hamil dikarenakan langkah yang mudah diterapkan dan dapat dilakukan secara mandiri dan berkelanjutan dirumah apabila kecemasan muncul lagi, sehingga dapat memberikan perasaan yang nyaman dan menyenangkan (Laili, 2017)

Gangguan akibat kecemasan yang dialami ibu akan menjadi kegawatdaruratan baik bagi ibu sendiri maupun janin dalam proses persalinannya, yang dapat menyebabkan lepasnya hormon stres antara lain Adreno Cortico Tropin Hormone (ACTH), kortisol, katekolamin, ß-Endorphin, Growth Hormone $(\mathrm{GH})$, prolaktin dan Lutenizing Hormone (LH)/ Folicle Stimulating Hormone (FSH). Lepasnya 
hormon-hormon stres tersebut mengakibatkan terjadinya vasokonstraksi sistemik, termasuk diantaranya konstraksi vasa utero plasenta yang menyebabkan gangguan aliran darah di dalam rahim, sehingga penyampaian oksigen ke dalam miometrium terganggu dan mengakibatkan lemahnya kontraksi otot rahim. Kejadian tersebut menyebabkan makin lamanya proses persalinan (partus lama) sehingga janin dapat mengalami kegawatan (fetal distress). Disamping itu dengan meningkatnya plasma kortisol, berakibat menurunkan respon imun ibu dan janin. Kondisi tersebut bisa mengarah pada kematian ibu dan janin. Jika kondisi ini dibiarkan maka angka mortalitas dan morbiditas pada ibu hamil akan semakin meningkat (Ekawaldi, 2014).

Menurut pendapat Mawardika et al., (2020) banyak upaya yang dapat dilakukan untuk menurunkan kecemasan, salah satunya secara nonfarmakologi berupa intervensi teknik relaksasi nafas. Relaksasi pernafasan merupakan latihan pernapasan dengan teknik bernapas secara perlahan dan dalam, menggunakan otot diafragma, sehingga memungkinkan abdomen terangkat perlahan dan dada mengembang penuh. Relaksasi pernafasan ini telah terbukti mampu menjadi salah satu metode pengobatan. Manfaat yang dapat dirasakan setelah melakukan teknik Relaksasi Nafas Dalam dapat menghilangkan nyeri, ketentraman hati, dan berkurangnya rasa cemas.

Hasil yang didapatkan dari fenomena dilapangan bahwa kecemasan ibu hamil dalam penelitian ini terjadinya penurunan tingkat kecemasan setelah diberikan relaksasi pernafasan, dimana banyak ibu yang awalnya merasa cemas tentang persalinannya serta khawatir tentang kondisinya, setelah diberikan intervensi ibu sudah merasa tidak cemas lagi dan merasa lebih tenang serta nyaman dan siap dalam mengahadapi persalinan dan kondisi bayinya. Hasil penelitian ini menunjukkan bahwa adanya pengaruh antara sebelum dan sesudah pemberikan intervensi relaksasi pernafasan terhadap tingkat kecemasan ibu hamil trimester III di Puskesmas Langsa Baro disebabkan karena relaksasi nafas dapat meningkatkan ventilasi paru dan meningkatkan oksigenasi darah yang memberikan ketenangan untuk menjalani dan menghadapi proses kehamilan.

\section{SIMPULAN}

Ada pengaruh relaksasi pernafasan terhadap kecemasan pada ibu hamil trimester III dengan kecemasan responden sebelum diberikan intervensi relaksasi pernafasan menunjukkan masih terdapat responden mempunyai tingkat kecemasan yang berat dan setelah diberikan intervensi relaksasi pernafasan menunjukkan tidak adanya responden yang mempunyai tingkat berat, kecemasan responden sebelum diberikan intervensi relaksasi pernafasan menunjukkan masih terdapat responden mempunyai tingkat kecemasan yang ringan-sedang dan setelah diberikan intervensi relaksasi pernafasan menunjukkan adanya penurunan responden mempunyai tingkat kecemasan yang ringan-sedang.

\section{SARAN}

Diharapkan tenaga kesehatan melakukan konseling kepada ibu yang akan bersalin tentang metode relaksasi pernapasan, untuk mengantisipasi kecemasan serta rasa takut pada ibu serta memberikan informasi tentang persiapan persalinan baik fisik dan psikis yang tenang atau rileks agar persalinan dapat berjalan dengan aman dan lancar.

Hasil penelitian ini diharapkan dapat menjadi bahan referensi guna melakukan peelitian yang sama, dan peneliti selanjutnya diharapkan dapat meneliti lebih lanjut dengan metode relaksasi lain seperti zikir, otot dan lainnya agar dapat mengahasilakn berbagai macam metode relaksasi untuk mengatasi kecemasan pada ibu.

\section{DAFTAR PUSTAKA}

Anggraieni, W. N. (2014). Pengaruh Terapi Relaksasi Zikir untuk Menurunkan Stres pada Penderita Hipertensi Esensial. Jurnal Intervensi Psikologi, 6(1).

Dinas Kesehatan Aceh. (2020). Profil Kesehatan Aceh Tahun 2019. Banda Aceh. Retrieved from www.dinkes.acehprov.go.id

Dinkes Kota Langsa. (2020). Profil Kesehatan Kota Langsa. Langsa.

Ekawaldi, I. Z. (2014). Efektifitas teknik relaksasi pernafasan untuk mengurangi kecemasan atlet futsal yang hendak bertanding. Semarang.

Hani, U. (2010). Asuhan Kebidanan dalam Asuhan Kehamilan Fisiologis. Jakarta: Salemba Medika.

Hikmawati, D. (2018). Penerapan Relaksasi Dzikir Untuk Mengurangi Tingkat Kecemasan Ibu Hamil Trimester III. Retrieved from http://elib.stikesmuhgombong.ac.id/894/

Kemenkes RI. (2018). Survei Demografi dan Kesehatan Indonesia (SDKI). Jakarta.

Kuswaningsih. (2020). Pengaruh Teknik Relaksasi Nafas Dalam Terhadap Kecemasan Pada Ibu Hamil Dengan Hipertensi Di Puskesmas Prangat Kabupaten Kutai Kartanegara. Kalimantan Timur. 
Laili, F. (2017). Pengaruh Teknik Relaksasi Nafas Dalam Terhadap Kecemasan Dalam Menghadapi Persalinan Pada Ibu Hamil. Jurnal Kebidanan, 3(3), 152-156.

Mawardika, T., Rahmawati, I. N., \& Kurniawati, W. (2020). Relaksasi pernafasan dan dzikir menurunkan tingkat kecemasan pada ibu hamil HIV positif: Literature review. Jurnal Penelitian Dan Pemikiran IImiah Keperawatan, 6(2), 101-108.

Na'im, N. J. (2010). Hubungan Dukungan Keluarga dengan Tingkat Kecemasan Ibu Primigravida Menghadapi Persalinan di Puskesmas Pamulang Kota Tanggerang Selatan. Jakarta.

Niko, P. F. (2018). Pengaruh Terapi Dzikir Untuk Menurunkan Kecemasan Pada Ibu Hamil. Jurnal ISLAMIKA, 01(01), 24-33.

Notoadmodjo, S. (2014). Metodologi Penelitian Kesehatan. Jakarta: PT. Rineka Cipta.

Pratiwi, W. R. (2019). Hubungan Tingkat
Kecemasan Ibu Hamil terhadap Risiko Melahirkan Bayi Berat Lahir Rendah di Puskesmas Rappang. Jurnal IImiah Kesehatan Iqra, 7(1).

Said. (2017). Potret Awal Tujuan Pembangunan Berkelanjutan (Sustainable Development Goals) di Indonesia. Jakarta. Retrieved from www. filantropi.or.id

Syafrie, I. R. (2017). Gambaran Pengetahuan Dan Kecemasan Ibu Hamil Trimester lii Dalam Menghadapi Persalinan Di Wilayah Kerja Puskesmas Muara Aman Kecamatan Lebong Utara, Kabupaten Lebong Tahun 2016. Journal of Midwifery, 5(1), 1-8.

Syufian, N. (2019). Pengaruh Terapi Zikir terhadap tingkat Kecemasan Pasien Pre Operasi Sectio Caesarea Di RSUD Dr. H. Moch. Ansari Saleh Banjarmasin. Dinamika Kesehatan Jurnal Kebidanan Dan Keperawatan, 10(2). 